\title{
Reversal of Syphilitic Hydrocephalus with Intravenous Penicillin
}

\author{
Mirco Cosottini, Mario Mascalchi, Gaetano Zaccara and Graziano Arnetoli
}

\begin{abstract}
Background: CSF shunting procedures are generally considered the fundamental therapy of syphilitic hydrocephalus. Methods: We followed up with CSF analysis and MR imaging a patient with progressive mental and gait disturbances and tetraventricular hydrocephalus due to tertiary syphilis who was treated for 14 days with high dose intravenous penicillin alone. Results: Clinical and CSF abnormalities resolved within a few months, whereas the hydrocephalus disappeared only 30 months after therapy. Conclusions: Before consideration of a CSF shunting procedure, a trial of high dose intravenous penicillin is warranted for patients with syphilitic hydrocephalus.
\end{abstract}

\begin{abstract}
RÉSUMÉ: Cure de l'hydrocéphalie syphilitique par la pénicilline intraveineuse. Introduction: La dérivation du LCR est généralement considérée comme la base du traitement de l'hydrocéphalie syphilitique. Méthodes: Nous avons suivi par analyse du LCR et par RMN un patient qui présentait une détérioration mentale et une instabilité à la marche progressives ainsi qu'une hydrocéphalie tétraventriculaire due à une syphilis tertiaire et qui avait été traité pendant 14 jours par de hautes doses de pénicilline intraveineuse seulement. Résultats: Les anomalies cliniques et du LCR sont rentrées dans l'ordre en quelques mois, alors que l'hydrocéphalie est disparue seulement 30 mois après le traitement. Conclusions: Avant de considérer la dérivation, un essai thérapeutique au moyen de pénicilline intraveineuse à haute dose est indiqué chez les patients qui présentent une hydrocéphalie syphilitique.
\end{abstract}

Can. J. Neurol. Sci. 1997; 24: 343-344

Hydrocephalus is a late complication of tertiary syphilis causing neurological deterioration and requiring CSF shunting procedures. ${ }^{1,4}$ We report a patient presenting with tertiary neurosyphilis and hydrocephalus which reversed after a course of intravenous penicillin.

\section{CASe Report}

A 44-year-old man was admitted to hospital in December 1988. In February 1988 he presented with mania for which he received lithium carbonate and carbamazepine without improvement. One month later his parents noted that he was confused, stammering, and walked unsteadily. At admission the patient was drowsy, inattentive and aggressive, showed spatio-temporal disorientation, made errors in simple problem solving and had auditory hallucinations. The neurological examination showed diffusely increased muscle stretch reflexes, bilateral Babinski signs, ankle clonus and hypermetria and tremor in the finger to nose test. No sensory abnormalities were present. The pupils and fundus were normal. The patient was dysarthric and showed moderate mental impairment but denied headache. He scored $16 / 30$ on the mini mental state examination. EEG showed diffuse slowing, more pronounced in the fronto-temporal regions. Blood examinations revealed TPHA $\gg 10240$, VDRL +++, FTA-ABS +++, FTA-ABS IgM ++--Test for the human immunodeficiency virus was negative. MR imaging showed moderate tetraventricular hydrocephalus with a patent cerebral aqueduct and a thick periventricular halo (Figure 1). The convexity subarachnoid spaces were effaced. Lumbar puncture yielded CSF at normal pressure with $86 \mathrm{mg} / 100 \mathrm{ml}$ total proteins (normal value $<50 \mathrm{mg} / 100$ $\mathrm{ml}$ ), $47 \mathrm{mg} / 100 \mathrm{ml}$ glucose (normal value $50-80 \mathrm{mg} / 100 \mathrm{ml}$ ) and 66 leukocytes $\mathrm{mm}^{3}$ with 49 lymphocytes. The ratio of CSF albumin to serum albumin (blood brain barrier index) was 0.0130 (normal value $<0.0065$ ), the $\mathrm{IgG}$ titer was $36.4 \mathrm{mg} / \mathrm{l}$ (normal value $<5.5 \mathrm{mg} / \mathrm{l}$ ) and the IgG index 2.54 (normal value $<0.7$ ). In the CSF, VDRL was +++ , TPHA $1: 2560$, FTA-ABS ++++, FTA-ABS IgM -. No clue concerning the date of the primary syphilitic infection was found on specific inquiry. Three days later an intravenous infusion of sodium penicillin
(4,000,000 IU every 4 hours) was started and continued for 14 days. No steroids were administered. The patient's mental condition showed prompt and progressive improvement. He was no more aggressive, was oriented in space and time and showed concern about his health. The CSF 11 days after beginning of therapy showed $90 \mathrm{mg} / 100 \mathrm{ml}$ total proteins, 28 leukocytes $\mathrm{mm}^{3}, 226 \mathrm{mg} / \mathrm{lgG}$ and TPHA $1: 2560$. One month later CSF protein content was normal $(38 \mathrm{mg} / 100 \mathrm{ml})$, whereas IgG $(24$ $\mathrm{mg} / \mathrm{l})$ and leukocytes $\left(16 \mathrm{~mm}^{3}\right)$ were still increased. Fourteen months later, CSF showed normal protein $(25 \mathrm{mg} / 100 \mathrm{ml})$, cells $\left(3 \mathrm{~mm}^{3}\right)$ and IgG $(4.5 \mathrm{mg} / \mathrm{l})$ content with TPHA 1:320. Further MR imaging examinations obtained 1 and 12 months after therapy showed no change, but a further study performed 30 months after the start of therapy showed disappearance of hydrocephalus and considerable reduction of periventricular signal changes (Figure 1). At that time an EEG was normal and neurological examination showed only mild sensory ataxia and increased reflexes to the lower limbs. No mental deterioration was present ( $27 / 30$ on the mini mental state examination). He returned to work and his neurological condition remained stable for 3 years when he died of lung cancer. Autopsy was not performed.

\section{Discussion}

The clinical presentation of mania, dysarthria, mental deterioration and bilateral pyramidal signs in our patient is consistent with the classical description of the pre-paralytic phase of tertiary syphilis. ${ }^{3}$ Initial and post-therapy CSF findings are also typical of this condition..$^{3,4.7}$

Syphilitic hydrocephalus is assumed to be due to adhesive

From the Clinica Neurologica II, Università di Firenze, Florence, Cattedra di Radiologia, Università di Pisa (M.M.), Pisa, Italy

RECEIVED DECEMBER 2, 1996. ACCEPTED JUNE 16, 1997.

Reprint requests to: Mario Mascalchi, Cattedra di Radiologia, Università di Pisa, Via Roma 67, 56125 Pisa, Italia. 


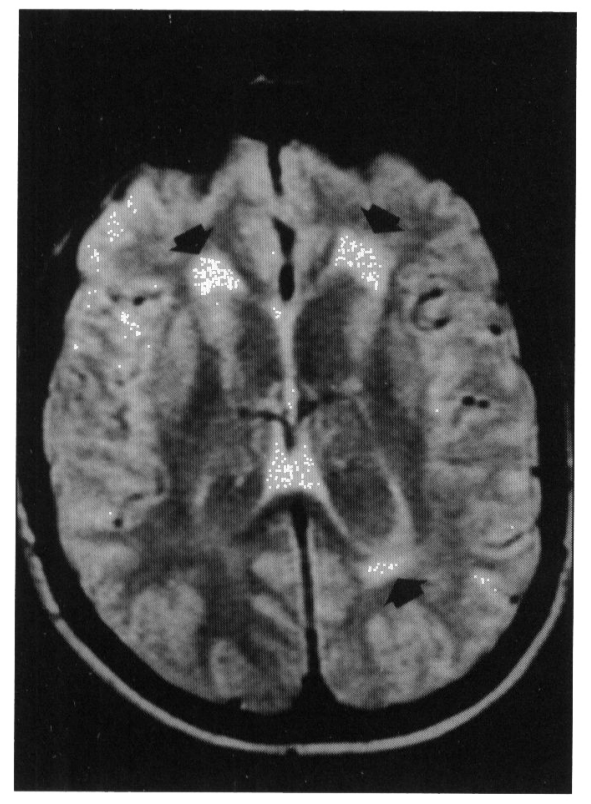

Figure 1: A) Axial proton density (TR 2240, TE 50) weighted spin echo $M R$ image at presentation shows moderate dilatation of the lateral ventricles and thick bifrontal and left occipital periventricular halo (arrows).

leptomeningitis causing block of the basal cisterns or fourth ventricle outlet foramina.$^{1,2,5}$ Clinical presentation includes acute hypertensive hydrocephalus ${ }^{5}$ or a chronic normal pressure hydrocephalus ${ }^{1.2}$ which generally are thought to require CSF shunting or evacuation procedures. We found in the literature only one case report of syphilitic normal pressure hydrocephalus, demonstrated by pneumoencephalography and isotope cisternography, the symptoms of which reversed after intravenous penicillin therapy. ${ }^{6}$ No radiological or cisternography follow-up data were available.

It must be emphasized that the disappearance of hydrocephalus in our patient occurred later than the CSF and clinical improvement. The features of this case suggest that the pathophysiology of hydrocephalus in tertiary syphilis involves an initial inflammatory phase that is responsive to intravenous penicillin but, if untreated, it can evolve into a second, fibrotic, phase which may require CSF shunting or evacuation.' Moreover, it suggests that some clinical features of the early stages of syphilitic general paresis, notably mental and gait deterioration, might be due to normal pressure hydrocephalus.

In conclusion, we consider that a trial of high dose intravenous penicillin therapy is warranted for patients presenting with tertiary neurosyphilis and hydrocephalus. Shunting proce-

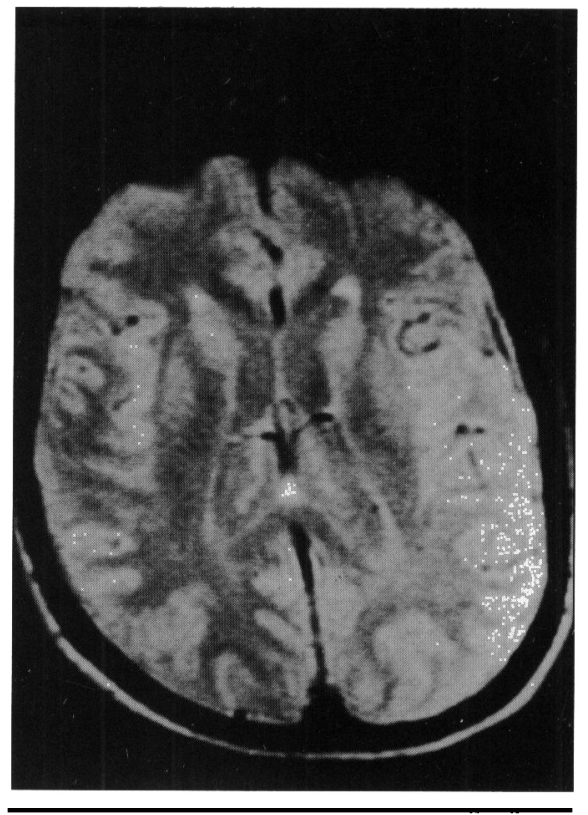

Figure 1: B) Axial proton density (TR 2240,TE 50) weighted spin echo image 30 months after intravenous penicillin therapy shows decreased ventricular size and reduction and disappearance of the frontal and occipital periventricular signal changes, respectively.

dures should be reserved for patients who fail to improve clinically after such therapy.

\section{ACKNOWLEDGEMENT}

We thank Mrs. Isabelle Bariller for revision of the text.

\section{REFERENCES}

1. Gimènez-Roldan $C$, Benito $C$, Martin $M$. Dementia paralytica: deterioration from communicating hydrocephalus. J Neurol Neurosurg Psychiatry 1979; 42: 501-508.

2. Lamy C, Eymard B, Lèger JM, Pierrot-Deseilligny C, Brunet $P$. Hydrocèphalie communicante révélatrice d'une neurosyphilis. Rev Neurol 1990; 146: 54-56.

3. Storm-Matthisen A. Syphilis. In: Vynken Bruyn, eds. Handbook of Clinical Neurology, Vol. 33, Amsterdam, Elsevier Publishers, 1978: 337-394.

4. Goodman LJ, Karakunis PH. Neurosyphilis. In: Vynken Bruyn, eds. Handbook of Clinical Neurology, Vol. 52, Amsterdam, Elsevier Publishers, 1988: 273-287.

5. Greenfield JG, Stern RO. Syphilitic hydrocephalus in the adult. Brain 1932; 55: 367-391.

6. Pedersen KK, Sorensen PS, Ankerhus J, Danielsen UT. Syphilitic normal pressure hydrocephalus. Acta Neurochir 1979; 48: 35-39.

7. Simon RP. Neurosyphilis. Arch Neurol 1985; 42: 606-613. 